\title{
Microstructures and Hardness Prediction of an Ultrafine-Grained Al-2024 Alloy
}

\author{
Ying Chen ${ }^{1, *} \mathbb{C}$, Yuanchen Tang ${ }^{1}$, Houan Zhang ${ }^{1}$, Nan $\mathrm{Hu}^{2}$, Nong Gao ${ }^{2}$ and Marco J. Starink ${ }^{2}$ \\ 1 Key Laboratory of Functional Materials and Applications of Fujian Province, Xiamen University of \\ Technology, Xiamen 361024, China; 1632062134@stu.xmut.edu.cn (Y.T.); ha_zhang@163.com (H.Z.) \\ 2 Engineering Materials, School of Engineering, University of Southampton, Southampton SO17 1BJ, UK; \\ nan.hu@siat.ac.cn (N.H.); N.Gao@soton.ac.uk (N.G.); M.J.Starink@soton.ac.uk (M.J.S.) \\ * Correspondence: cyj829@163.com; Tel.: +86-592-6291326
}

Received: 16 October 2019; Accepted: 29 October 2019; Published: 1 November 2019

\begin{abstract}
High-pressure torsion (HPT) is a high efficiency processing method for fabricating bulk ultrafine-grained metallic materials. This work investigates microstructures and evaluates the corresponding strengthening components in the center of HPT disks, where effective shear strains are very low. An Al-4.63Cu-1.51Mg (wt. \%) alloy was processed by HPT for 5 rotations. Non-equilibrium grain and sub-grain boundaries were observed using scanning transmission electron microscopy in the center area of HPT disks. Solute co-cluster segregation at grain boundaries was found by energy dispersive spectrometry. Quantitative analysis of X-ray diffraction patterns showed that the average microstrain, crystalline size, and dislocation density were $(1.32 \pm 0.07) \times 10^{-3}, 61.9 \pm$ $1.4 \mathrm{~nm}$, and $(2.58 \pm 0.07) \times 10^{14} \mathrm{~m}^{-2}$, respectively. The ultra-high average hardness increment was predicted on multiple mechanisms due to ultra-high dislocation densities, grain refinement, and co-cluster-defect complexes.
\end{abstract}

Keywords: high-pressure torsion; $\mathrm{Al}-\mathrm{Cu}-\mathrm{Mg}$ alloy; solute segregation

\section{Introduction}

High-pressure torsion (HPT) is a type of advanced severe plastic deformation processing (SPD) that can fabricate bulk metallic materials with ultrafine-grained microstructures and a high dislocation density [1,2]. HPT produces heterogeneous microstructures across the radius of the discs [2,3]. Compared to other SPD techniques, HPT has a higher efficiency for grain refinements and a good potential to improve the strength of metallic materials.

Al-Cu-Mg alloys, especially 2024-T351 alloys, are typically applied on lower wing structures of aircrafts because of their low mass density and good damage tolerance [4,5]. The hardness evolution, dislocation behavior, and grain refinement during HPT processing of Al-2024 alloys have been recently investigated [6]. Grain refinement to nano scales with high angle misorientations leading to superplastic deformation through boundary sliding has been reported [7].

During artificial ageing after conventional processing, $\mathrm{S}\left(\mathrm{Al}_{2} \mathrm{CuMg}\right)$-phase precipitates contribute to strength increase [5,8-10]. Research using atom probe tomography (i.e., three-dimensional atom probe technique) showed that $\mathrm{Cu}-\mathrm{Mg}$ co-clusters are responsible for rapid hardening of Al-2024 alloy at room temperature and very low temperatures [11]. In HPT processing, $\mathrm{Cu}-\mathrm{Mg}$ co-clusters segregate to form co-cluster-defect complexes, which further improve the strength and hardness of Al-2024 alloys [12,13]. It has been shown that increases in hardness near the edge of the HPT disk result from high dislocation densities, strong grain refinement, precipitation, and short-range order (SRO) complexes. However, no such investigation has as yet been carried out for the center of HPT disks, where effective shear strains are very low. The main objective of this paper is to characterize the 
inhomogeneous microstructures and to evaluate the corresponding strengthening components near the center of an HPT disk.

\section{Materials and Methods}

This work was carried out on Al-2024 discs with dimensions of $9.8 \mathrm{~mm}$ diameter and $8.5 \pm 0.2 \mathrm{~mm}$ height. Samples were subjected to HPT for 5 rotations under a pressure of $6 \mathrm{GPa}$ and a speed of $1 \mathrm{r} / \mathrm{min}$. Further details of the HPT processing are provided in [14].

After HPT, some samples were ground and polished to $80 \mu \mathrm{m}$ thickness using SiC papers and punched small slices with $3 \mathrm{~mm}$ diameter at the center of the disk and at $2.5 \mathrm{~mm}$ distance from the center. Both 5r-HPT slices and Al-2024 T351 slices were then dimpled to $\sim 10 \mu \mathrm{m}$ using a Model 656 dimple grinder (Gatan Inc. USA. A Gatan PIPS II Model 695 precision ion polishing system) was used to achieve the thin foils [15]. Liquid $\mathrm{N}_{2}$ was used to stabilize temperature at $-180{ }^{\circ} \mathrm{C}$. The scanning/transmission electron microscope (S/TEM) tests were carried out at $200 \mathrm{kV}$ using a FEI TalosTMF200S microscope (FEI, Brno-Černovice, Czech Republic), equipped with energy dispersive spectrometry (EDS, Oxford Instrument, High Wycombe, UK).

Some $5 \mathrm{r}$-HPT samples were carefully punched to obtain central disks $5 \mathrm{~mm}$ in diameter across the disk center and polished to a mirror-like surface. X-ray-diffraction (XRD) was conducted using a Siemens D5000 diffractometer (Bruker, Germany) at $0.02^{\circ} \%$ s. Further details of XRD experimental methods of the XRD spectra are described in $[12,13]$. In order to calculate the microstrain and diffraction domain size (i.e., crystalline size), the collected data was performed by full-peak refinement using the software Materials Analysis Using Diffraction (MAUD, version 1.999, L. Lutterotti, Italy). Vickers hardness was performed across the radius within this area of the disk with a load of $500 \mathrm{~g}$ for a dwell time of $15 \mathrm{~s}(0.5 \mathrm{~mm}$ interval between two dots along the radius).

\section{Results}

The STEM micrographs in Figure 1 show the microstructures of the Al-2024 alloy in the as-received condition T351. This T351 conditioning involved solution treatment, $2 \%$ stretch, and subsequent aging at room temperature. The bright field (BF) in Figure 1a and high-angle annular dark field (HAADF) images in Figure $1 \mathrm{~b}$ illustrate the microstructures with grain sizes of $2.3 \pm 0.5 \mu \mathrm{m}$ (obtained by the average line intercept method [16]). The corresponding solute EDS mappings of $\mathrm{Cu}, \mathrm{Mg}, \mathrm{Mn}$, and $\mathrm{Al}$ in Figure $1 \mathrm{~d}$ show that the dispersoid and intermetallic phases on grain boundaries and within the grain interiors contain $\mathrm{Al}, \mathrm{Cu}$, and $\mathrm{Mn}$. Comparison of these observations with previous work indicates the standard T- $\mathrm{Al}_{20} \mathrm{Cu}_{2} \mathrm{Mn}_{3}$ phase, which has an orthorhombic structure with lattice parameters of $a=$ $2.42 \mathrm{~nm}, b=1.25 \mathrm{~nm}, c=0.775 \mathrm{~nm}[9,17,18]$; whilst the other is the $\mathrm{Al}_{7} \mathrm{Cu}_{2}(\mathrm{Fe}, \mathrm{Mn})$ phase, which has a tetragonal structure of $\mathrm{P} 4 / \mathrm{mnc}$ and lattice parameters of $a=0.6336 \mathrm{~nm}, c=1.487 \mathrm{~nm}$ [5]. Figure 1e presents the cross-section of one $\mathrm{Cu}$ - and $\mathrm{Mn}$-containing, rod-like precipitate in the $\mathrm{Al}$ matrix. The corresponding fast Fourier transform (FFT) pattern of the precipitate is shown in Figure 1f. This phase is the $\mathrm{Al}_{20} \mathrm{Cu}_{2} \mathrm{Mn}_{3}$ phase, which contains two sets of interfaces parallel to two low index planes of the T-phase, namely $\{200\}_{\mathrm{T}}$ and $\{101\}_{\mathrm{T}}$ [18]. The $\mathrm{Al}_{20} \mathrm{Cu}_{2} \mathrm{Mn}_{3}$ phase is a dispersoid phase that cannot be dissolved by heat treatments; in conventional thermomechanical processing of $\mathrm{Al}-\mathrm{Cu}$ type alloys, it acts to limit grain growth [9].

Figure 2a,c shows further TEM bright field and dark field images of an HPT center sample. From the selected area diffraction pattern in Figure $2 b$, the grains within the aperture of $0.02 \mu \mathrm{m}^{2}$ have a very small angle of misorientation. Figure $2 \mathrm{~d}$ presents the morphological characteristics of dislocations and sub-grains using TEM dark field imaging. They are attributed to specific "non-equilibrium" grain boundaries, which contain an excessive density of extrinsic dislocations and additional local lattice strains [19-21]. The average grain size of the 5r-HPT center sample is measured using the modified average line intercept method and taken as $d=1.455 \mathrm{~L}$, where $L$ is the average line intercept [16]. Measuring over 300 grains in 30 TEM images, the average grain size of a 5r-HPT sample at the center is 
$215 \pm 55 \mathrm{~nm}$. The average grain size of a 5r-HPT sample near the edge of the sample, where higher strains were generated during the HPT processing, is $157 \pm 30 \mathrm{~nm}$, as seen in [13].
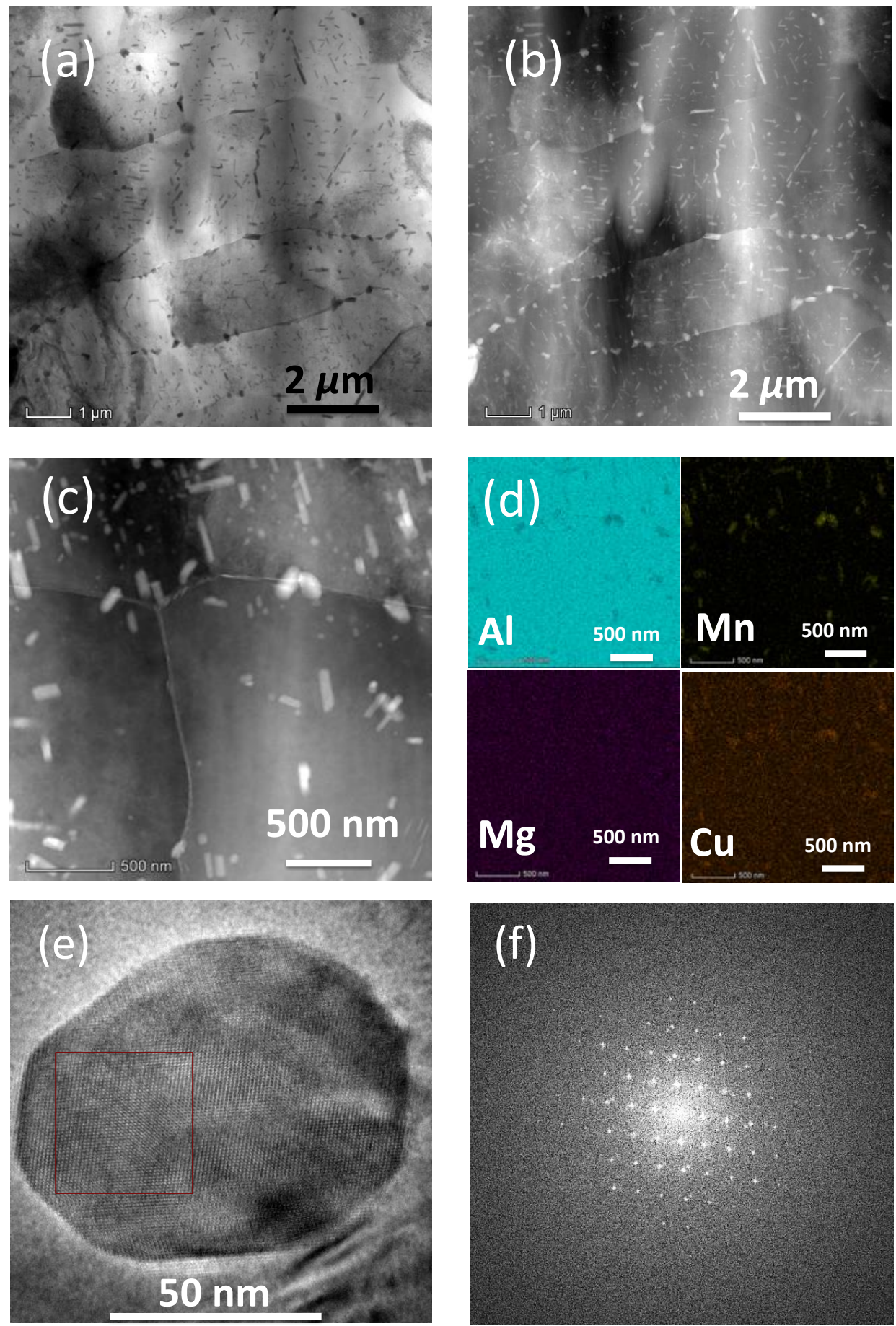

Figure 1. Microstructures of the T351 Al-4.63Cu-1.51Mg (wt.\%) alloy without processing high-pressure torsion: (a) scanning transmission electron microscopy bright field (STEM-BF) image; (b) scanning transmission electron microscopy dark field (STEM-DF) image; (c) scanning transmission electron microscopy high-angle annular dark field (STEM-HAADF) image; (d) energy dispersive spectrometry (EDS) mappings of different solute elements; (e) high resolution TEM image of $\mathrm{Al}_{7} \mathrm{Cu}_{2} \mathrm{Mn}$ phase (f) corresponding fast Fourier transform (FFT) image of the square area in (e). 

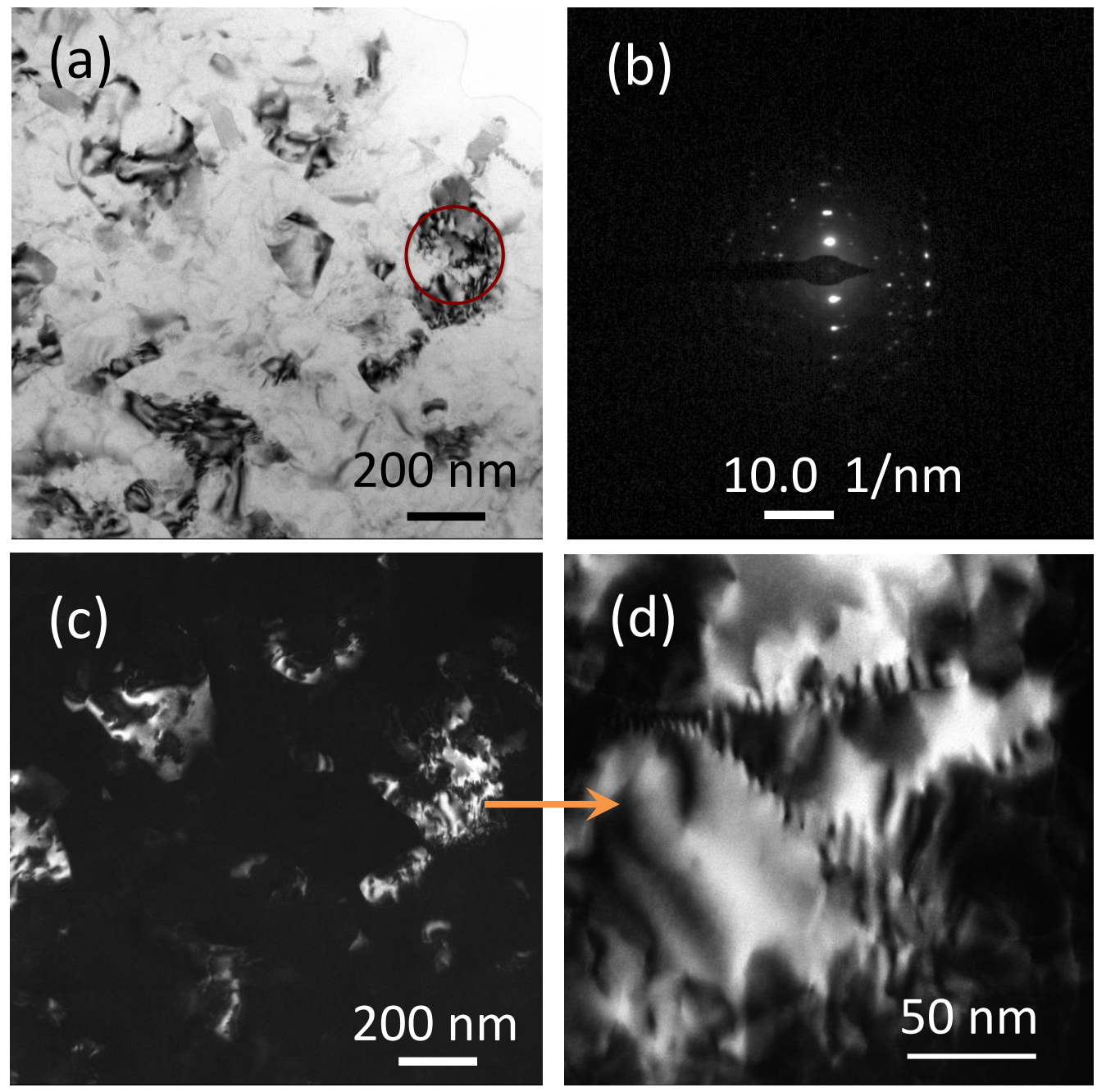

Figure 2. Microstructures of the $5 r$ high-pressure torsion ( $5 r-H P T)$ center sample: (a) transmission electron microscopy bright field (TEM-BF) image; (b) selected area diffraction of red circle in (a); (c) transmission electron microscopy dark field TEM-DF image; (d) enlarged area in (c).

The bright field and annular dark field micrographs of center areas in the HPT processed disk are shown in Figure 3a,b. These STEM micrographs show grains refined to the ultra-fine range, with locally high densities of dislocations. A large number of dislocations and sub-grain boundaries were observed within the grain interiors, as shown in orange dashed circles. Figure $3 \mathrm{~d}$ shows an EDS line profile across a grain boundary in Figure 3c. $\mathrm{Cu}$ and $\mathrm{Mg}$ atoms on grain boundaries take the original place of $\mathrm{Al}$ atoms, as seen in Figure 3e. Figure $3 \mathrm{f}$ shows the atomic-resolved HAADF-STEM image of grain matrix interiors, indicating lattice bending and disordering as a result of severe plastic deformation.

Figure 4 shows an XRD pattern measured from the center area of the HPT disk. Microstrain $\varepsilon$ and diffraction domains $D_{\mathrm{c}}$ cause the $\mathrm{Al}$ XRD profile broadening. The average dislocation density of this $5 \mathrm{r}-\mathrm{HPT}$ center sample is estimated by the following equation as [22,23],

$$
\rho=\frac{2 \sqrt{3}\left\langle\varepsilon^{2}\right\rangle^{1 / 2}}{D_{c} b}
$$

Using the software MAUD [24-26], the microstrain, size of diffraction domain, and the dislocation density are $(1.32 \pm 0.07) \times 10^{-3}, 61.9 \pm 1.4 \mathrm{~nm}$, and $(2.58 \pm 0.07) \times 10^{14} \mathrm{~m}^{-2}$, respectively. The anisotropic profile broadening related to anisotropic crystalline shape, strain, or planar defects was negligible [13]. 

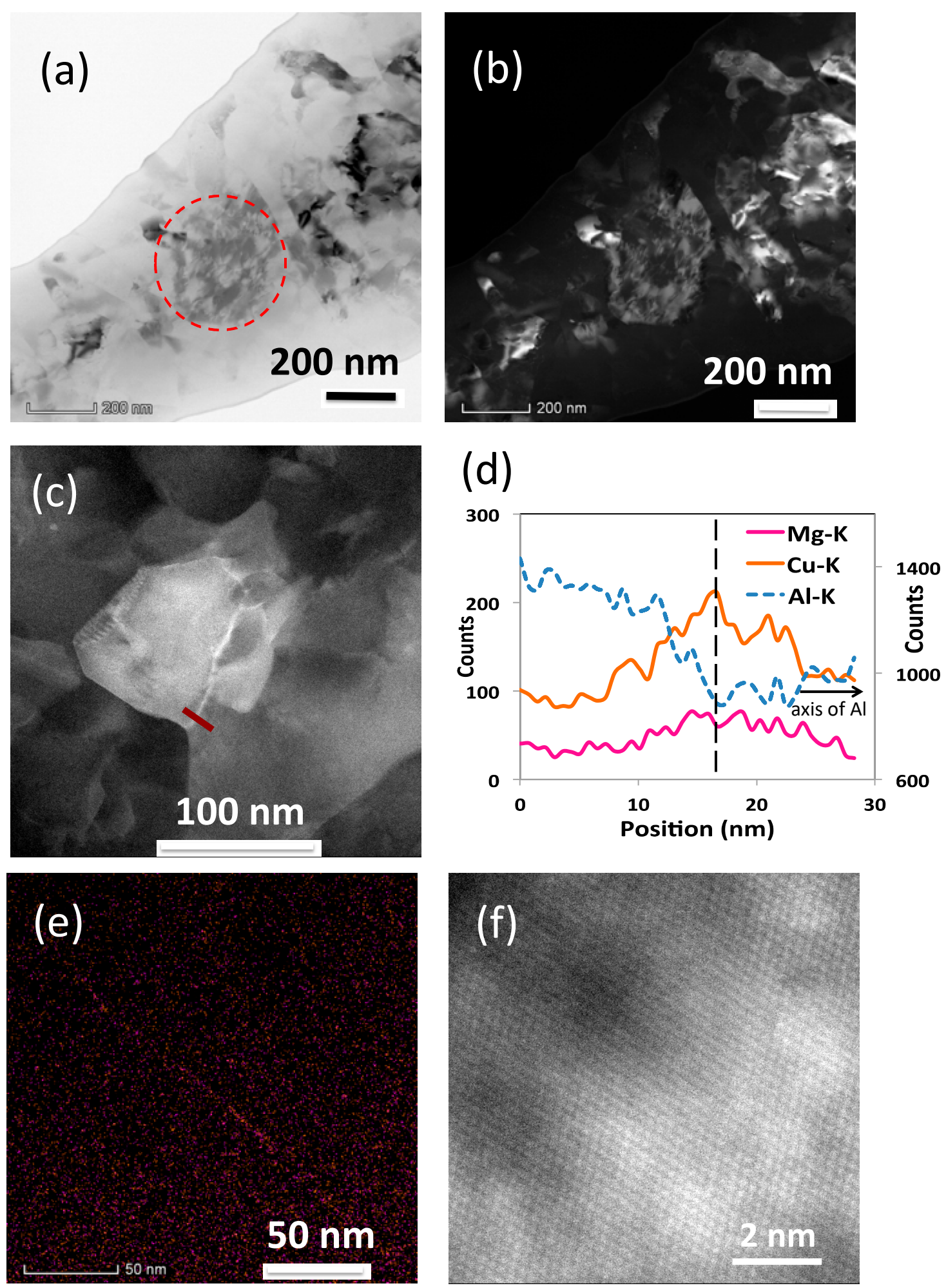

Figure 3. STEM images of 5r-HPT center sample: (a) BF image; (b) annular dark field (ADF) image $(\mathbf{a}, \mathbf{b})$ (i.e., at disk center); (c) HAADF image; (d) line profiles of $\mathrm{Al}, \mathrm{Cu}$, and $\mathrm{Mg}$ across the grain boundary in (c), the red line; (e) EDS mappings of $\mathrm{Cu}-\mathrm{Mg}$ co-clusters around a grain boundary; (f) the high-resolution atomic image (c-f) (i.e., at $2.5 \mathrm{~mm}$ to the disk center). 


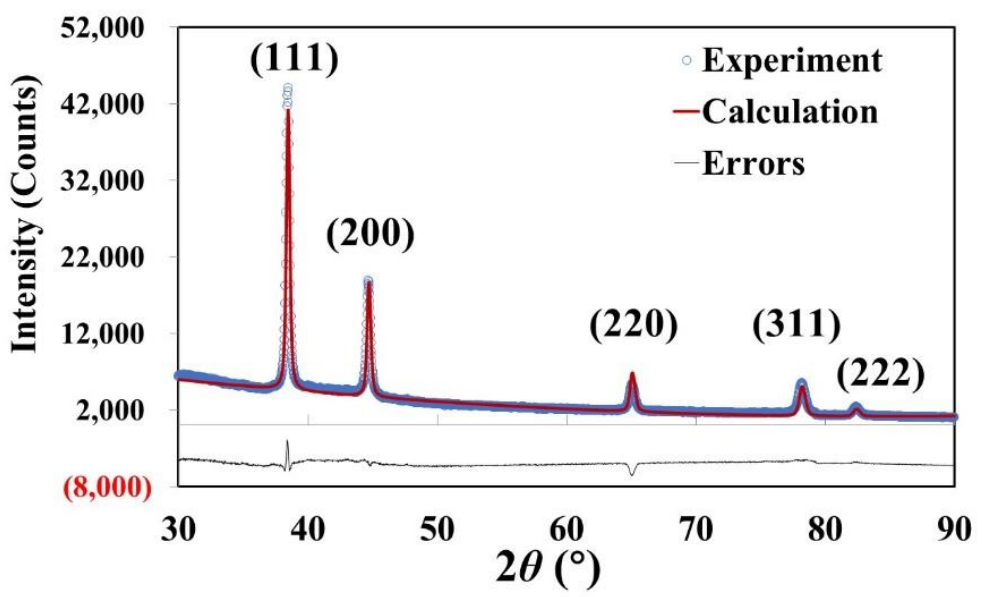

Figure 4. X-ray diffraction of a $5 \mathrm{r}$-HPT sample punched in the central area $(0<r<2.5 \mathrm{~mm}, r$ is the distance to disk center). The experimental data is the blue circle, while the red solid line is the simulated pattern. The difference between experimental data and the simulated pattern is under the diffraction pattern.

The micro hardness close to the center of the disk was measured across the radius within the center area. Figure 5 illustrates the hardness distribution across the radius ranging from 200 to $250 \mathrm{HV}$. The hardness increases with increasing distance to the center. The micro-hardness reached the saturated value, which was reported in [13].

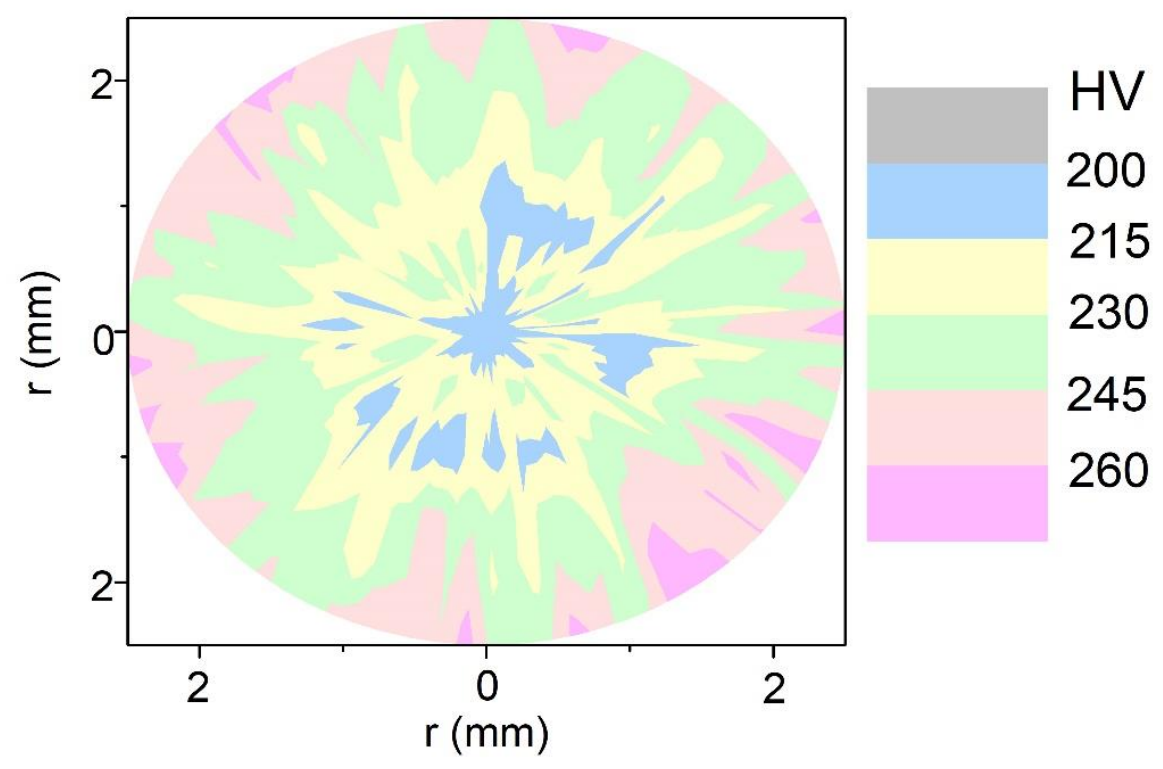

Figure 5. Vickers hardness mapping of the center area in an HPT disk.

\section{Discussion}

It is well known that the microhardness of HPT samples correlates to locations in HPT disks and the number of rotations. The formula of the equivalent von Mises strain $\varepsilon_{e q}$ is

$$
\varepsilon_{e q}=\frac{2 \pi r N}{\sqrt{3} h}
$$

where $r$ is the distance to the center of the disk, $N$ is the number of turns, and $h$ is the thickness of the HPT disk [1,2]. Indeed, the true plastic flow during HPT processing is complex. As described in literature [26,27], the HPT process satisfies the power strain hardening function associated with 
a self-similarity theory. Equation (2) is a simple mathematical description of the process when the exponent of power function is 1 for shear strain and von Mises strain [26]. As the deformation exceeds a certain range of von Mises strains, both the microstructure and the strain hardening of the material reach a saturated level. The average hardness near the edge is $\sim 256 \mathrm{HV}$ (see our previous work [12]). In HPT processing, the shear strain at the HPT center is zero, however, the hardness near the center is $~ 90$ HV larger than the T351 sample (143 HV). This can be attributed to the strain rate sensitivity coefficient of HPT-processed disks. Only when the strain rate sensitivity coefficient of the material is high enough strain localization will not take place [27]. Furthermore, another factor causing the hardness increment and its inhomogeneous distributions are the radial gradient of torsional shearing strains [28], which causes the formation of geometrically necessary dislocations. Also, the heterogeneous evolution of microstructures, as seen in Figure 2, contributes to the increase in hardness. Furthermore, solute clusters were shown to segregate to grain boundaries in STEM-EDS images, as illustrated in Figure 4. Solute segregations at the grain boundaries reduce the overall Gibbs free energy and enhance the thermal stability of grain boundaries $[19,29]$. $\mathrm{Cu}$ and $\mathrm{Mg}$ have a trend to cluster together, which contributes to a significant strengthening at the very early stage of ageing in $\mathrm{Al}-\mathrm{Cu}-\mathrm{Mg}$ alloys $[11,30,31]$. Co-cluster segregation to the grain boundaries and dislocation, which are both present at high densities, have been reported to further improve the overall Vickers hardness of HPT-processed Al-2024 alloys [12,13]. Cluster segregation to grain boundaries will lower the energy barrier of $\mathrm{S}^{\prime}$ - and S-phase nucleation and accelerate their precipitation. As a result, the precipitating temperature of a 5r-HPT sample has been found to be lower than that of a T351 sample in differential scanning calorimetry experiments [13].

The increase of hardness during HPT results from the combination of dislocations, refined grains, atom solutions, and cluster formation. In this section, we will show how the hardness of a 5r-HPT sample near the center areas can be estimated by a suitable model, incorporating these mechanisms as follows. The increase in hardness due to dislocations is described by $[12,13]$,

$$
\Delta H V_{d}=C M \alpha_{1} G b \sqrt{\rho_{\text {total }}}
$$

where $C$ is a dimensionless constant of 3 that describes the relationship between yield strength and hardness [32]; $\alpha_{1}$ is a dimensionless constant equaling 0.3 [12]; $M$ is the mean orientation factor, 2.6 [33,34]; $G$ is the shear modulus, taken as $27 \mathrm{GPa}$ [12]; and $\mathrm{b}$ is the Burgers vector, $0.286 \mathrm{~nm}[12,13]$. The dislocation density, $\rho_{\text {total }}$, is obtained by quantitative analysis of the XRD broadened profile in Figure 4 , which provides the dimensions of the center of the disk as $\rho_{\text {total }}=2.58 \pm 0.07 \times 10^{14} \mathrm{~m}^{-2}$. The hardness increment due to dislocation densities is $\sim 31.2 \mathrm{HV}$, measured by quantitative calculation. The hardness increment due to grain refinement can be estimated using the Hall-Petch equation [35],

$$
\Delta H V_{\mathrm{gb}}=C \frac{k_{H P}}{d^{\frac{1}{2}}}
$$

where $d$ is the grain size and $k_{H P}$ is the Hall-Petch constant, taken as $0.062 \mathrm{MPa} / \mathrm{m}^{-1 / 2}[36,37]$. In our HPT sample, the grain size near the center of the HPT disk was measured as $d=215 \pm 55 \mathrm{~nm}$. The hardness increases by $43 \pm 7 \mathrm{HV}$ as a result of the ultrafine-grain size.

The diffusion of solutes to grain boundaries and dislocations, where they can form co-clusters and cluster-defect complexes, is a temperature-dependent process. The effective diffusion distance can be described as [19]

$$
\lambda=\sqrt{6 D t}
$$

where $t$ is the diffusion time and $D$ is the diffusion coefficient.

$$
D=D_{0} \exp \left(-\frac{Q}{R T}\right)
$$

Here, $Q$ is the activation energy [38]. The hardening due to co-clusters and cluster-defect complexes is mainly due to short range order (SRO) hardening (i.e., it depends on the average enthalpy 
of co-clusters and cluster-defect complexes, $\Delta H_{A-B-d i s}$, and the amount of $\mathrm{Cu}$ and $\mathrm{Mg}$ atoms in the $\mathrm{Cu}-\mathrm{Mg}$ co-clusters, $y_{\mathrm{C} u}$ and $\left.y_{M g}\right)[12,13]$. The SRO hardening can be approximated by [12]

$$
\Delta H V_{S R O}=C M \Delta \tau_{S R O} \cong C M \frac{8}{3 \sqrt{3}} \frac{\Delta H_{A-B-d i s}}{b^{3}}\left(y_{C u}+y_{M g}\right)
$$

In addition, modulus hardening contribution also occurs due to clustering. Solute hardening strongly depends on the concentrations of solute atoms $c_{M g}$ and $c_{C u}$, which follow the formula [39,40],

$$
\Delta H V_{s s}=C M\left(k_{M g} c_{M g}+k_{C u} c_{C u}\right)
$$

In previous work [13], these 3 strengthening contributions were calculated for 5r-HPT samples near the edge of the disk. As the chemical composition and temperature are similar between edge and center, we will assume that these 3 strengthening contributions are not dependent on the position in the sample. Thus, we are assuming any differences in cluster density over the sample are limited and do not cause significant variations in hardness. The equilibrium between atom solution and co-cluster segregation is assumed to be independent of position, as with concentrations of solute atoms in the matrix (i.e., $c_{M g}$ and $c_{C u}$ ) and in the $\mathrm{Cu}-\mathrm{Mg}$ co-clusters $\left(y_{C u}\right.$ and $y_{M g}$ ). The $\Delta H V_{s S}$ and $\Delta H V_{S R O}$ values equal those of a 5r-HPT sample near the edge, which are 15.7 and $5.1 \mathrm{HV}$, respectively.

The overall average hardness predicted by this model at the center area is $232 \pm 7 \mathrm{HV}$, which is within the error margin and equal to the measured hardness near the center, which averaged $230 \mathrm{HV}$. This close correspondence indicates that the present model is solid. It is noted that the predicted (and measured) hardness consists of strongly increased dislocation hardening of $31 \mathrm{HV}$, grain boundary hardening of $43 \mathrm{HV}$, and hardening due to co-clusters and cluster-defect complexes, with the latter (co-clusters and cluster-defect complexes) at $\sim 107 \mathrm{HV}$ providing the strongest overall contribution to the hardness at the center.

\section{Conclusions}

An Al-2024 T351 alloy was processed by high-pressure torsion for 5 rotations. The hardness increases with distance from the center of the HPT-processed disk, and this inhomogeneous hardness was caused by heterogeneous microstructures across the radius of the HPT disks. STEM-EDS showed solute atoms and clusters were segregated to grain boundaries. The origin of the hardness increment $(\sim 90 \mathrm{HV})$ in the center areas is attributed to the combination of dislocation hardening, grain refinement hardening, and hardening due to co-clusters and cluster-defect complexes.

Author Contributions: Conceptualization, Y.C.; formal analysis, Y.C.; funding acquisition, Y.C. and H.Z.; investigation, Y.T. and N.H.; supervision, H.Z., N.G., and M.J.S.; writing-original draft, Y.C.; writing一review and editing, Y.C., N.G., and M.J.S.

Funding: This work was supported by the National Natural Science Foundation of China (Grant No. 51601162), Fujian Natural Science Foundation (Grant No. 2017J01490 and No. 2019J01870), Xiamen Municipal Bureau Science and Technology Project (Grant No. 3502Z20179025). The corresponding author thanks the Program for Innovative Research Team in Science and Technology in Fujian Province University (IRTSTFJ) and Program for Oversea High-Level Personnel of Xiamen ([2016] 314-03).

Acknowledgments: We greatly appreciate Zhiyang Yu and Jinging Sun for help with STEM/TEM.

Conflicts of Interest: The authors declare no conflict of interest. The funders had no role in the design of the study; in the collection, analyses, or interpretation of data; in the writing of the manuscript, or in the decision to publish the results.

\section{References}

1. Zhilyaev, A.P.; Langdon, T.G. Using high-pressure torsion for metal processing: Fundamentals and applications. Prog. Mater. Sci. 2008, 53, 893-979. [CrossRef] 
2. Vinogradov, A.; Estrin, Y. Analytical and numerical approaches to modelling severe plastic deformation. Prog. Mater. Sci. 2018, 95, 172-242. [CrossRef]

3. Edalati, K.; Horita, Z. A review on high-pressure torsion (HPT) from 1935 to 1988. Mater. Sci. Eng. A 2016, 652, 325-352. [CrossRef]

4. Starink, M.J.; Gao, N.; Kamp, N.; Wang, S.C.; Pitcher, P.D.; Sinclair, I. Relations between microstructure, precipitation, age-formability and damage tolerance of $\mathrm{Al}-\mathrm{Cu}-\mathrm{Mg}-\mathrm{Li}(\mathrm{Mn}, \mathrm{Zr}, \mathrm{Sc}$ ) alloys for age forming. Mater. Sci. Eng. A 2006, 418, 241-249. [CrossRef]

5. Wang, S.C.; Lefebvre, F.; Yan, J.L.; Sinclair, I.; Starink, M.J. VPPA welds of Al-2024 alloys: Analysis and modelling of local microstructure and strength. Mater. Sci. Eng. A 2006, 431, 123-136. [CrossRef]

6. Vafaei, R.; Toroghinejad, M.R.; Pippan, R. Evaluation of mechanical behavior of nano-grained $2024 \mathrm{Al}$ alloy during high pressure torsion (HPT) process at various temperatures. Mater. Sci. Eng. A 2012, 536, 73-81. [CrossRef]

7. Alhamidi, A.; Horita, Z. Grain refinement and high strain rate superplasticity in alumunium 2024 alloy processed by high-pressure torsion. Mater. Sci. Eng. A 2015, 622, 139-145. [CrossRef]

8. Wang, S.C.; Starink, M.J. The assessment of GPB2/S structures in Al-Cu-Mg alloys. Mater. Sci. Eng. A 2004, 386, 156-163. [CrossRef]

9. Wang, S.C.; Starink, M.J. Precipitates and intermetallic phases in precipitation hardening Al-Cu-Mg-(Li) based alloys. Int. Mater. Rev. 2005, 50, 193-215. [CrossRef]

10. Parel, T.S.; Wang, S.C.; Starink, M.J. Hardening of an Al-Cu-Mg alloy containing Types I and II S phase precipitates. Mater. Des. 2010, 31, S2-S5. [CrossRef]

11. Sha, G.; Marceau, R.K.W.; Gao, X.; Muddle, B.C.; Ringer, S.P. Nanostructure of aluminium alloy 2024: Segregation, clustering and precipitation processes. Acta Mater. 2011, 59, 1659-1670. [CrossRef]

12. Chen, Y.; Gao, N.; Sha, G.; Ringer, S.P.; Starink, M.J. Strengthening of an Al-Cu-Mg alloy processed by high-pressure torsion due to clusters, defects and defect-cluster complexes. Mater. Sci. Eng. A 2015, 627, 10-20. [CrossRef]

13. Chen, Y.; Gao, N.; Sha, G.; Ringer, S.P.; Starink, M.J. Microstructural evolution, strengthening and thermal stability of an ultrafine-grained Al-Cu-Mg alloy. Acta Mater. 2016, 109, 202-212. [CrossRef]

14. Starink, M.J.; Qiao, X.G.; Zhang, J.; Gao, N. Predicting grain refinement by cold severe plastic deformation in alloys using volume averaged dislocation generation. Acta Mater. 2009, 57, 5796-5811. [CrossRef]

15. Ma, K.; Hu, T.; Yang, H.; Topping, T.; Yousefiani, A.; Lavernia, E.J.; Schoenung, J.M. Coupling of dislocations and precipitates: Impact on the mechanical behavior of ultrafine grained Al-Zn-Mg alloys. Acta Mater. 2016, 103, 153-164. [CrossRef]

16. Thorvaldsen, A. The intercept method-1. Evaluation of grain shape. Acta Mater. 1997, 45, 587-594. [CrossRef]

17. Wang, S.C.; Li, C.Z.; Yan, M.G. Determination of structure of $\mathrm{Al}_{20} \mathrm{Cu}_{2} \mathrm{Mn}_{3}$ phase in $\mathrm{Al}-\mathrm{Cu}-\mathrm{Mn}$ alloys. Mater. Res. Bull. 1989, 24, 1267-1270.

18. Chen, Y.Q.; Pan, S.P.; Liu, W.H.; Liu, X.; Tang, C.P. Morphologies, orientation relationships, and evolution of the T-phase in an Al-Cu-Mg-Mn alloy during homogenisation. J. Alloys Compd. 2017, 709, 213-226. [CrossRef]

19. Sauvage, X.; Enikeev, N.; Valiev, R.; Nasedkina, Y.; Murashkin, M. Atomic-scale analysis of the segregation and precipitation mechanisms in a severely deformed Al-Mg alloy. Acta Mater. 2014, 72, 125-136. [CrossRef]

20. Sauvage, X.; Ganeev, A.; Ivanisenko, Y.; Enikeev, N.; Murashkin, M.; Valiev, R. Grain Boundary Segregation in UFG Alloys Processed by Severe Plastic Deformation. Adv. Eng. Mater. 2012, 14, 968-974. [CrossRef]

21. Sauvage, X.; Wilde, G.; Divinski, S.V.; Horita, Z.; Valiev, R.Z. Grain boundaries in ultrafine grained materials processed by severe plastic deformation and related phenomena. Mater. Sci. Eng. A 2012, 540, 1-12. [CrossRef]

22. Williamson, G.K.; Smallman, R.E., III. Dislocation densities in some annealed and cold-worked metals from measurements on the X-ray debye-scherrer spectrum. Philos. Mag. 1956, 1, 34-46. [CrossRef]

23. Zhao, Y.H.; Liao, X.Z.; Jin, Z.; Valiev, R.Z.; Zhu, Y.T. Microstructures and mechanical properties of ultrafine grained $7075 \mathrm{Al}$ alloy processed by ECAP and their evolutions dring annealing. Acta Mater. 2004, 52, 4589-4599. [CrossRef]

24. Ferrari, M.; Lutterotti, L. Method for the simultaneous determination of anisotropic residual stresses and texture by X-ray diffraction. J. Appl. Phys. 1994, 76, 7246-7255. [CrossRef] 
25. Lutterotti, L.; Gialanella, S. X-ray diffraction characterization of heavily deformed metallic specimens. Acta Mater. 1998, 46, 101-110. [CrossRef]

26. Beygelzimer, Y.; Kulagin, R.; Toth, L.S.; Ivanisenko, Y. The Self-similarity theory of high pressure torsion. Beilstein. J. Nanotechnol. 2016, 7, 1267-1277. [CrossRef]

27. Kulagin, R.; Beygelzimer, Y.; Ivanisenko, Y.; Mazilkin, A.; Hahn, H. Modelling of high pressure torsion using FEM. Procedia Eng. 2017, 207, 1445-1450. [CrossRef]

28. Kratochvíl, J.; Kružík, M.; Sedláček, R. A model of ultrafine microstructure evolution in materials deformed by high-pressure torsion. Acta Mater. 2009, 57, 739-748. [CrossRef]

29. Chookajorn, T.; Murdoch, H.A.; Schuh, C.A. Design of Stable Nanocrystalline Alloys. Science 2012, 337, 951-954. [CrossRef]

30. Ringer, S.P.; Sakurai, T.; Polmear, I.J. Origins of hardening in aged Al-Cu-Mg-(Ag) alloys. Acta Mater. 1997, 45, 3731-3744. [CrossRef]

31. Starink, M.J.; Wang, S.C. The thermodynamics of and strengthening due to co-clusters: General theory and application to the case of Al-Cu-Mg alloys. Acta Mater. 2009, 57, 2376-2389. [CrossRef]

32. Meyers, M.A.; Mishra, A.; Benson, D.J. Mechanical properties of nanocrystalline materials. Prog. Mater. Sci. 2006, 51, 427-556. [CrossRef]

33. Starink, M.J.; Wang, S.C. A model for the yield strength of overaged Al-Zn-Mg-Cu alloys. Acta Mater. 2003, 51, 5131-5150. [CrossRef]

34. Zhang, J.; Gao, N.; Starink, M.J. Microstructure development and hardening during high pressure torsion of commercially pure aluminium: Strain reversal experiments and a dislocation based model. Mater. Sci. Eng. A 2011, 528, 2581-2591. [CrossRef]

35. Hansen, N. Hall-Petch relation and boundary strengthening. Scr. Mater. 2004, 51, 801-806. [CrossRef]

36. Shanmugasundaram, T.; Heilmaier, M.; Murty, B.S.; Sarma, V.S. On the Hall-Petch relationship in a nanostructured Al-Cu alloy. Mater. Sci. Eng. A 2010, 527, 7821-7825. [CrossRef]

37. Starink, M.J.; Cheng, X.; Yang, S. Hardening of pure metals by high-pressure torsion: A physically based model employing volume-averaged defect evolutions. Acta Mater. 2013, 61, 183-192. [CrossRef]

38. Shewmon, P.G. Diffusion in Solids; McGraw-Hill: New York, NY, USA, 1963; p. 200.

39. Wang, S.C.; Zhu, Z.; Starink, M.J. Estimation of dislocation densities in cold rolled Al-Mg-Cu-Mn alloys by combination of yield strength data, EBSD and strength models. J. Microsc. 2005, 217, 174-178. [CrossRef]

40. Starink, M.J.; Gao, N.; Davin, L.; Yan, J.; Cerezo, A. Room temperature precipitation in quenched Al-Cu-Mg alloys: A model for the reaction kinetics and yield strength development. Philos. Mag. 2005, 85, 1395-1417. [CrossRef]

(C) 2019 by the authors. Licensee MDPI, Basel, Switzerland. This article is an open access article distributed under the terms and conditions of the Creative Commons Attribution (CC BY) license (http://creativecommons.org/licenses/by/4.0/). 